\title{
BLEVE: THE CASE OF WATER AND A HISTORICAL SURVEY
}

\author{
Behrouz Hemmatian $^{1}$, Joaquim Casal ${ }^{2}$, Eulàlia Planas ${ }^{2}$, Davood Rashtchian ${ }^{1, *}$
}

${ }^{1}$ Center for Process Design, Safety and Loss Prevention (CPSL), Chemical and Petroleum Engineering Department, Sharif University of Technology, Tehran, Iran

${ }^{2}$ Centre for Technological Risk Studies (CERTEC), Barcelona East School of Engineering (EEBE), Universitat Politècnica de Catalunya, BarcelonaTech (UPC), Eduard Maristany 10-14, 08019Barcelona, Catalonia, Spain

\begin{abstract}
After a short update of the current more accepted definition of BLEVE, the special features of water BLEVEs are analyzed. The stronger overpressure wave generated in the case of water as compared to that of other substances is justified in terms of volume change. Through a comparison with liquefied pressurized propane, three possibilities are analyzed: the simultaneous contribution of both the liquid and the preexisting vapor, the contribution of the liquid flash vaporization, and the contribution of the pre-existing vapor. Also a historical survey on a set of 202 BLEVE accidents -the largest sample of BLEVE accidents surveyed until nowis presented. LPG was the most common substances in this set of accidents. However, water and LNG (11\% of water and $4 \%$ of LNG in the studied cases) have also been involved. Impact failure $(44.8 \%)$ and human factor $(30.3 \%)$ were the most common causes of BLEVEs. Transport, storage, process plants, and transfer were the activities in which more accidents occurred.
\end{abstract}

\section{Keywords}

BLEVE; overpressure; steam boilers; historical analysis

* Corresponding author:

E-mail address: $\underline{\text { rashtchian@ } @ \text { sharif.edu }}$ (D. Rashtchian) 


\section{Introduction}

Among the different possible major accidents, Boiling Liquid Expanding Vapor Explosions (BLEVEs) keep occurring from time to time. A number of equipment and activities can originate them: steam boilers, liquefied gas storage tanks, road and rail tankers, etc. Even though their frequency seems to have decreased in the last decades, their effects keep being potentially very strong and the consequences on people can be very severe.

Quite recently (August 8, 2018) a BLEVE followed by a fireball occurred in a highway near Bologna (Italy), after a tanker transporting LPG and a lorry collided. Two persons were killed and about 60 injured by the effects of the explosion and the fire.

Two different physical effects are associated to a BLEVE: overpressure wave and ejected fragments; furthermore, serious thermal effects can occur if a flammable substance is involved, or, in some cases, toxic effects depending on the substance (for example, ammonia) (Abbasi and Abbasi, 2007).

Both mechanical and thermal effects have been studied by a number of authors. Concerning the thermal effects, in many cases their consequences on people are more severe than those associated with blast wave and ejected fragments (Birk et al., 2013); as the thermal phenomenon (fireball) lasts a certain time, this has allowed the registration of an important number of photos and films, i.e., experimental data at large scale that have been used for its mathematical modeling. The blast wave has also been studied, both experimentally and by using data from accidental large-scale explosions (see, for example, Bubbico and Marchini, 2008, and Birk et al., 2018).

Due to the fact that, in the case of a flammable substance, the thermal effects are quite important and visible and often graphically recorded, the acronym BLEVE has often been used as a synonymous of the fireball. This is why many of these explosions occurred with nonflammable substances have not been registered in the diverse accident data bases as BLEVEs, but with the general name of "explosion". This is, for example, the case of steam boilers, even if most steam boiler explosions are really a BLEVE.

In this communication, these concepts are revised, with special emphasis on the case of water, and a historical survey on a set of 202 BLEVE accidents (the largest set analyzed up to now) is performed to analyze the main causes and features of the occurrence of this accident.

\section{When is an explosion a BLEVE?}

After the BLEVE (Boiling Liquid Expanding Vapor Explosion) was described for the first time by Smith, Marsh, and Walls (Abbasi and Abbasi, 2007), a number of researchers have contributed to increase the knowledge on this accident. There has been some evolution concerning the exact definition of a BLEVE and which explosions should be considered as such.

Reid (1979), through an accurate analysis of the phenomenon, considered the superheat limit temperature $\left(\mathrm{T}_{\mathrm{sl}}\right)$ as a required condition for an explosion to be a BLEVE, defining this phenomenon as "the sudden loss of containment of a liquid that is at or above its superheating temperature limit". At this condition, due to the sudden depressurization, there is homogeneous nucleation in the whole mass of liquid and a sudden and important increase of volume. This 
practically instantaneous flashing of liquid produces a strong blast wave. At this situation, the explosion should be classified as a BLEVE. And according to this theory, if the temperature of the liquid at the moment of the vessel failure is not equal or higher than its superheat limit temperature, the explosion will not be a BLEVE, and its severity will be lower.

However, none of the different thermodynamic models proposed can justify an abrupt change in the overpressure at $\mathrm{T}_{\mathrm{sl}}$. Salla et al. (2006) arrived at the conclusion that $\mathrm{T}_{\mathrm{sl}}$ corresponds to the situation in which the energy transferred between the cooling liquid and the vaporizing liquid fractions is at its maximum, leading the remaining liquid to a minimum content of energy.

Some authors, as for example Birk et al. (1993, 2007), performed BLEVE experiments and concluded that BLEVE explosions occurred at temperatures lower than $\mathrm{T}_{\mathrm{sl}}$. Thus, Reid's theory is not applied nowadays, even though it can be useful for a better understanding of the BLEVE mechanism, and should be restricted to ideal, low scale laboratory conditions. In fact, this theory does not imply that the overall energy released in the explosion increases due to the fact that a different phenomenon occurs if the explosion takes place at a temperature equal or higher than the superheat limit one. What it would imply really is that, due to the fact that the boiling dynamics is much faster, practically instantaneous, the same energy would give rise to a higher overpressure and, therefore, to a much more severe explosion. Finally, another phenomenon that can have an important influence in many real cases and which would imply again a behavior different from that assumed in Reid's theory is the probable temperature stratification in the liquid phase (Scarponi et al., 2018). When this occurs, there can be a strong temperature gradient in the liquid, the hottest layers being at the liquid surface, thus originating a much faster pressure built-up in the vapor zone (i.e., in the vessel).

Another point which has also originated some controversy is related to the substance involved in the explosion. For example, some authors (Napier and Roopchand, 1986; Bernatik et al., 2011; Pitblado et al., 2011) considered that a BLEVE could not occur with liquefied natural gas (LNG), even though BLEVEs have occurred really with this material. Finally, as commented before, there is also some confusion between the phenomena of BLEVE and fireball.

The definition of this type of explosion commonly accepted nowadays is "a BLEVE is an explosion resulting from the failure of a vessel containing a liquid at a temperature significantly above its boiling point at atmospheric pressure" (CCPS, 1994).

\section{BLEVE overpressure}

One of the most common accidental scenarios leading to a BLEVE is the fire engulfment of a pressurized vessel. As the vessel heating proceeds the pressure inside it increases and, simultaneously, its wall weakens due to the increase of temperature; this effect is especially important in the upper section of the vessel, where the wall is not in contact with the liquid (Birk et al., 2006). And, after a certain time, the vessel fails and there is a violent phenomenon consisting in the expansion of the pre-existing vapor and the partial flash vaporization of the liquid; the practically instantaneous increase in volume originates the explosion with an overpressure wave and, often, ejection of vessel fragments. The overpressure wave can be very high in the near field (Laboureur et al., 2015). 
There is now some discussion concerning the respective contributions to the overpressure wave of these two phenomena, the expansion of the pre-existing vapor and the expansion of the vapor originated by the explosive boiling of the liquid. Among the existing mathematical models for predicting the peak overpressure of the explosion, some authors (Prugh, 1991; Planas et al., 2004) have taken both phenomena into consideration; others (Casal and Salla, 2006) have considered only the contribution of the liquid boiling; and finally, some others (Birk et al., 2007, 2018) consider that the expansion of the pre-existing vapor is the sole contribution to the maximum peak overpressure due to the faster phenomenon of vapor expansion as compared to the vaporization-and-expansion of the liquid. Of course, the respective contributions to overpressure wave of liquid vaporization and pre-existing vapor will depend on the masses of each phase present in the vessel.

In order to give an approximate idea of the differences that these assumptions can imply in the estimation of the peak overpressure, this overpressure has been calculated in the next section by assuming a) only the contribution of liquid flash vaporization (Casal and Salla, 2006), b) the contribution of the liquid vaporization plus that due to the pre-existing vapor (Prugh, 1991; Planas et al., 2004), and c) contribution of preexisting vapor (Birk et al., 2007, 2018; Johnson et al., 1990). The calculation has been performed for the same amount of two substances, water and propane

\section{The case of water}

A quite interesting case is that of vessels containing water at a relatively high temperature and pressure, which certainly can undergo a BLEVE if the vessel collapses and fails for any reason. Steam boilers are a good example. Although safety measures (liquid level controls, pressure relief valves, etc.) are provided, it is a fact that steam boiler explosions occur from time to time, due to the very high number of this equipment existing in many industries around the world. Two types of explosions can occur in a boiler: a) a fuel-air explosion in the furnace, and b) a BLEVE. This second case is much more frequent than the first one, but in most cases these explosions are not registered as BLEVEs, due essentially to the fact that water is not flammable and, therefore, no fireball follows the explosion. This is undoubtedly the reason why the number of water BLEVEs in most surveys and in the historical analysis included in the next section is rather low.

However, the effects of these explosions are very severe, the overpressure being usually significantly stronger than that generated in the explosion of vessels containing the same mass of other materials. This different behavior can be explained in terms of the physical change underwent by the liquid and vapor in the explosion, which will depend on the involved material. Here it has been analyzed for water and propane. Three options have been assumed, as previously mentioned: a) simultaneous contribution of both the liquid and the preexisting vapor, b) contribution of the liquid flash vaporization and c) contribution of the pre-existing vapor.

\section{a) Simultaneous contribution of the liquid and the preexisting vapor}

Fig. 1 shows the comparison of the energy released $\left(\mathrm{kJ} / \mathrm{m}^{3}\right.$ of vessel) by the explosion of a vessel containing water and another one containing propane. The calculation has been 
performed taking into account the contribution of both the expansion of the pre-existing vapor and that of the vapor produced by the flash partial vaporization of the liquid, by applying the method described by Hemmatian et al. (2017). The vessel conditions assumed for both cases have been a pressure of 8.4 bar abs. and saturated conditions (i.e., a temperature of $172.5^{\circ} \mathrm{C}$ for water and $20{ }^{\circ} \mathrm{C}$ for propane), and the released energy has been calculated for different filling levels (FL).

As it can be seen, the energy released is much higher for the case of water than for propane, assuming the same bursting pressure. For example, for a filling level of 50\% (FL $=0.5)$, the energy released in the case of water would be approximately $11.2 \mathrm{MJ} \mathrm{m}^{-3}$ and for propane would be $3.9 \mathrm{MJ} \mathrm{m}^{-3}$. This behavior can be explained as a function of the amount of vapor generated in the flash vaporization of the liquid in each case and on the different rate of volume increase with the changing conditions (before and after the explosion) for the two substances.

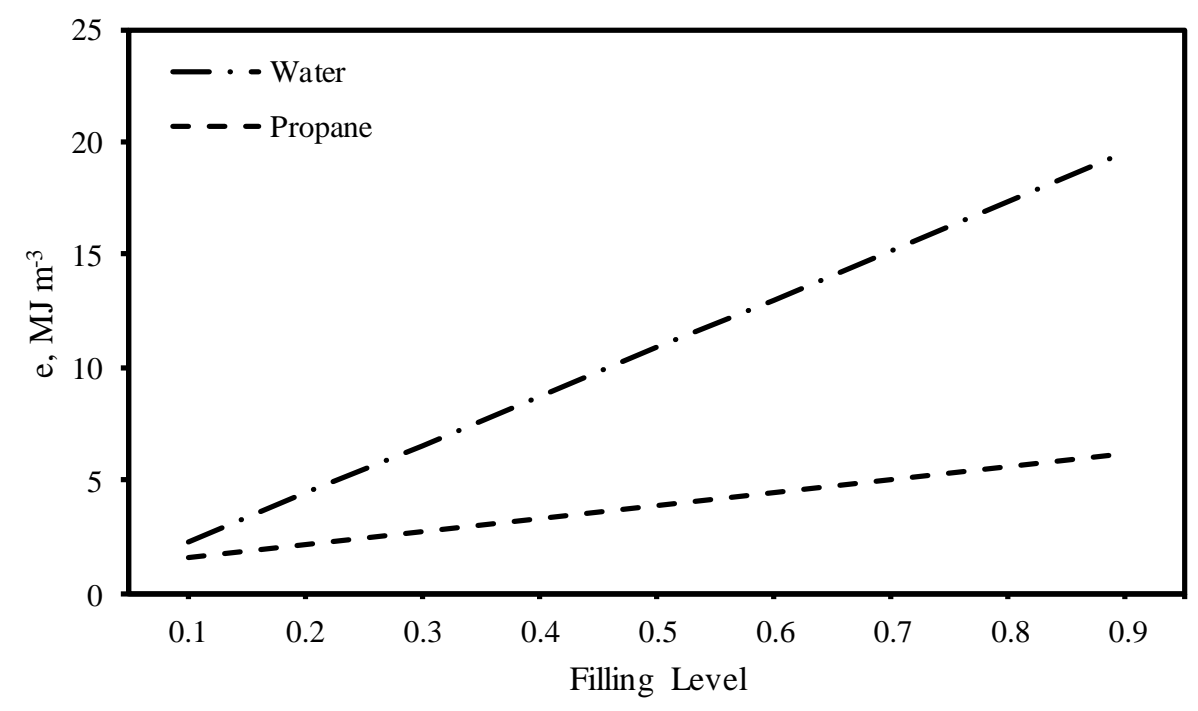

Fig. 1. Comparison of the energy released in the BLEVE of water and propane vessels at 8.4 bar and saturated temperature of $172.5^{\circ} \mathrm{C}$ for water and $20^{\circ} \mathrm{C}$ for propane.

\section{b) Contribution of the liquid flash vaporization}

Concerning the flash vaporization of the liquid in the vessel at the moment of the explosion, in the case of water, for each $\mathrm{kg}$ of liquid $0.134 \mathrm{~kg}$ of vapor are generated; this vapor (at $100{ }^{\circ} \mathrm{C}$ ) has a volume of $0.227 \mathrm{~m}^{3}$, this implying an increase in volume of $0.227-0.000134=0.2269$ $\mathrm{m}^{3}$ per $\mathrm{kg}$ of liquid in the vessel. Instead, in the case of propane each $\mathrm{kg}$ of liquid (with a volume of 0.711 liters) generates $0.352 \mathrm{~kg}$ of vapor, with a volume (at $-42{ }^{\circ} \mathrm{C}$ ) of $0.152 \mathrm{~m}^{3}$; the increase in volume is only $0.152-0.00071=0.1513 \mathrm{~m}^{3}$ per kilogram of liquid. Therefore, the ratio of volume changes water/ propane is:

Ratio of volume change water/propane in the flash vaporization $=0.2269 / 0.1513=1.5$

If only the contribution of liquid flash vaporization is taken into account (Casal and Salla, 2006), the superheating energy for both substances can be calculated (same vessel conditions): 
water:

$$
\mathrm{SE}=721-418.9=302 \mathrm{~kJ} \mathrm{~kg}^{-1}
$$

overpressure energy (irreversible process): $0.05 \cdot 302=15.1 \mathrm{~kJ} \mathrm{~kg}^{-1}$

propane: $\quad \mathrm{SE}=250-100.2=149.8 \mathrm{~kJ} \mathrm{~kg}^{-1}$

overpressure energy (irreversible process): $0.05 \cdot 149.8=7.49 \mathrm{~kJ} \mathrm{~kg}^{-1}$

Ratio of superheating energy water/propane $=15.1 / 7.49=2$

Even though these two ratios will change according to the vessel condition at the moment of the explosion, they are the explanation of why the steam boiler BLEVEs are so severe as compared to the explosions involving other materials.

\section{c) Contribution of the pre-existing vapor}

If, as some authors have proposed, only the first peak of the BLEVE (associated to the expansion of the pre-existing vapor just before the explosion) is the responsible of the peak overpressure (Birk et al., 2007, 2018; Johnson et al., 1990), then the increase in volume for water and propane, respectively, would be:

water: volume of $1 \mathrm{~kg}$ of vapor at $8.4 \mathrm{bar}$ abs and $172.5^{\circ} \mathrm{C}: 0.225 \mathrm{~m}^{3}$

volume at $1 \mathrm{~atm}$ and $100{ }^{\circ} \mathrm{C}=1.694 \mathrm{~m}^{3}$

volume increase: $1.694-0.225=1.469 \mathrm{~m}^{3} \mathrm{~kg}^{-1}$

propane: volume of $1 \mathrm{~kg}$ of vapor at 8.4 bar abs. and $20^{\circ} \mathrm{C}: 0.055 \mathrm{~m}^{3}$

volume at $1 \mathrm{~atm}$ and $-42^{\circ} \mathrm{C}: 0.4319 \mathrm{~m}^{3}$

volume increase: $0.432-0.055=0.377 \mathrm{~m}^{3} \mathrm{~kg}^{-1}$

Ratio of vapor volume change water/propane $=1.469 / 0.377=3.9$

Again, the different increase in volume due to the explosion justifies the higher peak overpressures usually reached with water BLEVEs.

\section{Occurrence of BLEVEs: a historical survey}

The historical analysis of BLEVE accidents is an interesting way to understand them better, as it can give a good overview of this phenomenon and which important factors play a role in it. A first historical analysis restricted to fire domino effect had been done with 127 cases (Hemmatian et al., 2015); this set has now been enlarged to 202, including other initiating events. MHIDAS (Major Hazard Incident Data Service) database (2007) was used to obtain some data. Other databases were also consulted: Analysis, Research and Information on Accidents (ARIA) (2012), Major Accident Reporting System (MARS) (2012), and Failure and ACcidents Technical information System (FACTS) (2010). The lack of information in some accidents was fulfilled by getting the assistance of other available resources such as the U.S. Chemical Safety Board (2012), the U. S. National Transport Safety Board (2013) and the National Fire Protection Association (2012). Microsoft Access ${ }^{\circledR}$ was used in order to manage and classify the data and to avoid recording more than once a given accident.

Only accidents occurred after $1^{\text {st }}$ January 1960 have been taken into account, in order to obtain results useful and representative of the nowadays industry and transport main features (Hemmatian et al., 2014). This survey considers accidents occurred in process plants, in storage 
areas and in the transportation of hazardous materials (road, rail, and ship); it also includes accidents that have occurred because of natural events such as earthquakes or floods.

\subsection{Distribution of accidents according to the time and location}

The frequencies of the BLEVE accidents as a function of time have been plotted in Fig 2. The highest frequency belongs to the 70's (24.8\%). The occurrence of this type of accidents seems to decrease afterward, although a clear trend cannot be really observed. A fact that could have some influence is the much better access to information on major accidents (BLEVE included) in the last decades; this could contribute to increase the frequency of registered cases.

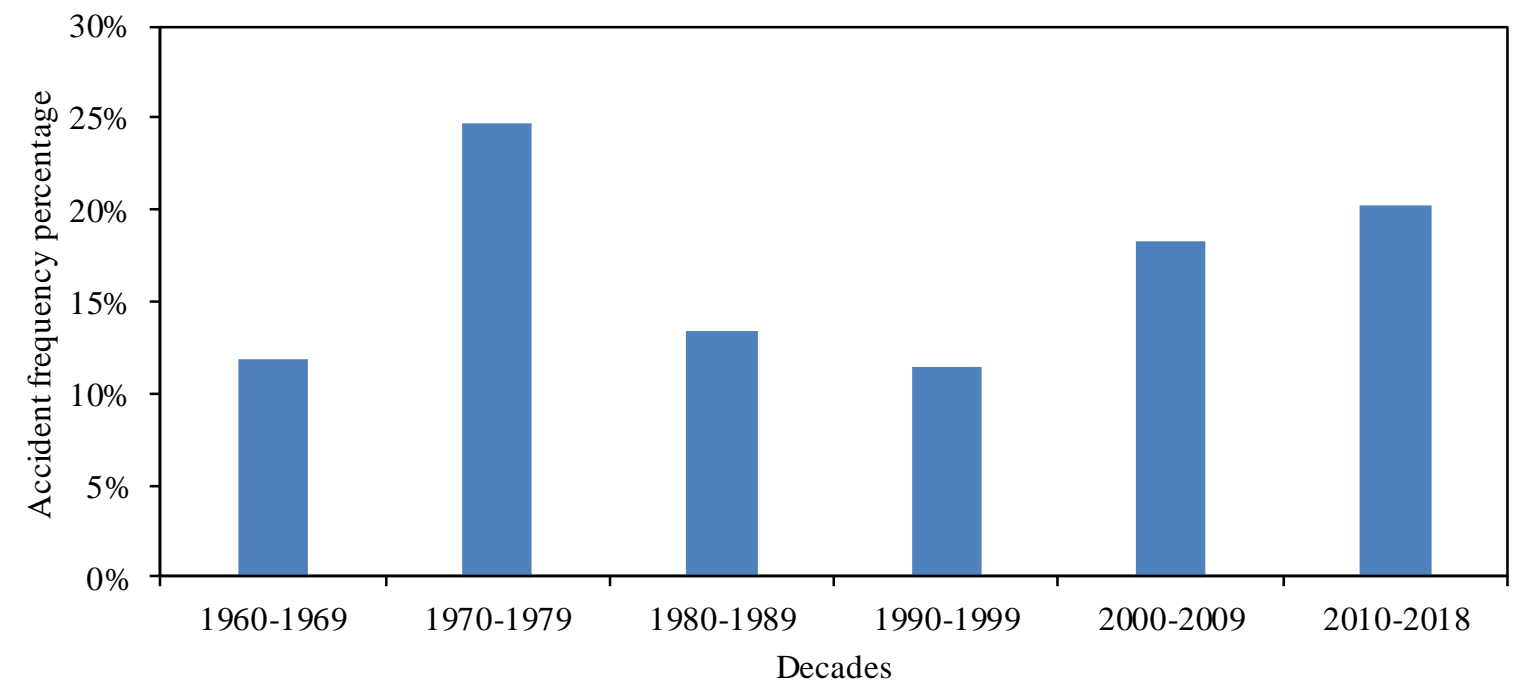

Fig. 2. Distribution of BLEVEs over the time.

The selected accidents have also been classified by their region. This type of classification was done by considering different factors such as political and development-based criteria. Countries in the world were classified into three groups:

- European Union (19.8\%),

- other developed countries: Australia, Canada, Japan, New Zealand, Switzerland, Norway and the United States $(51 \%)$,

- rest of the world $(29.2 \%)$.

In fact, we assume that this criterion can imply some bias in the statistical analysis, as both the geopolitical and economic circumstances of some countries have considerably evolved since the 1960s; however, as other previous analyses have also used it (Darbra et al., 2010; Abdolhamidzadeh et al., 2011), it seems reasonably to keep it.

According to this classification, the highest percentage $(70.8 \%)$ is found in the developed countries. This should be attributed to the presence of an important number of plants and to the associated transportation and storage infrastructures in these countries. Moreover, in developed countries, due to the existing policies and institutions in the fields of safety and environment, more information about the occurred accidents is available. 
Fig. 3 shows the frequencies of BLEVEs as a function of time in the three different groups of countries; even though there is an important dispersion of data, the general trend of the frequency is clear: the contribution of developing countries has increased in recent years, while it has decreased in developed ones and keeps essentially constant in the EU. 
BLEVEs in European Union

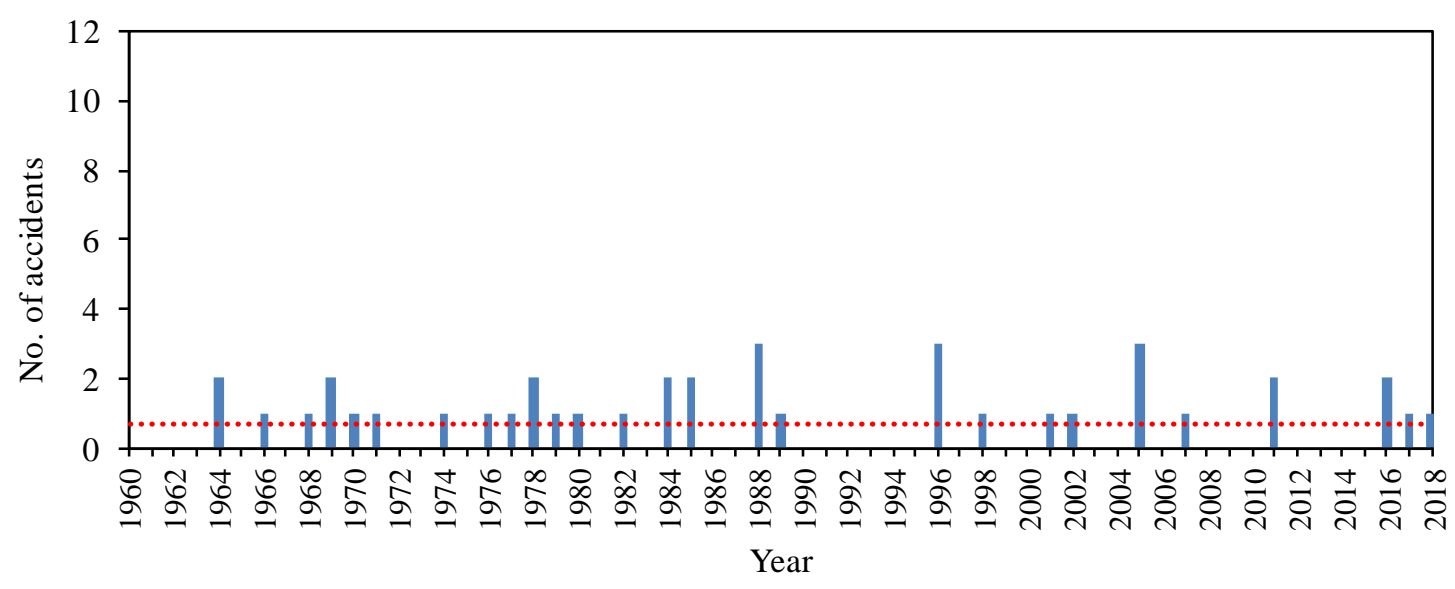

BLEVEs in other develped countries

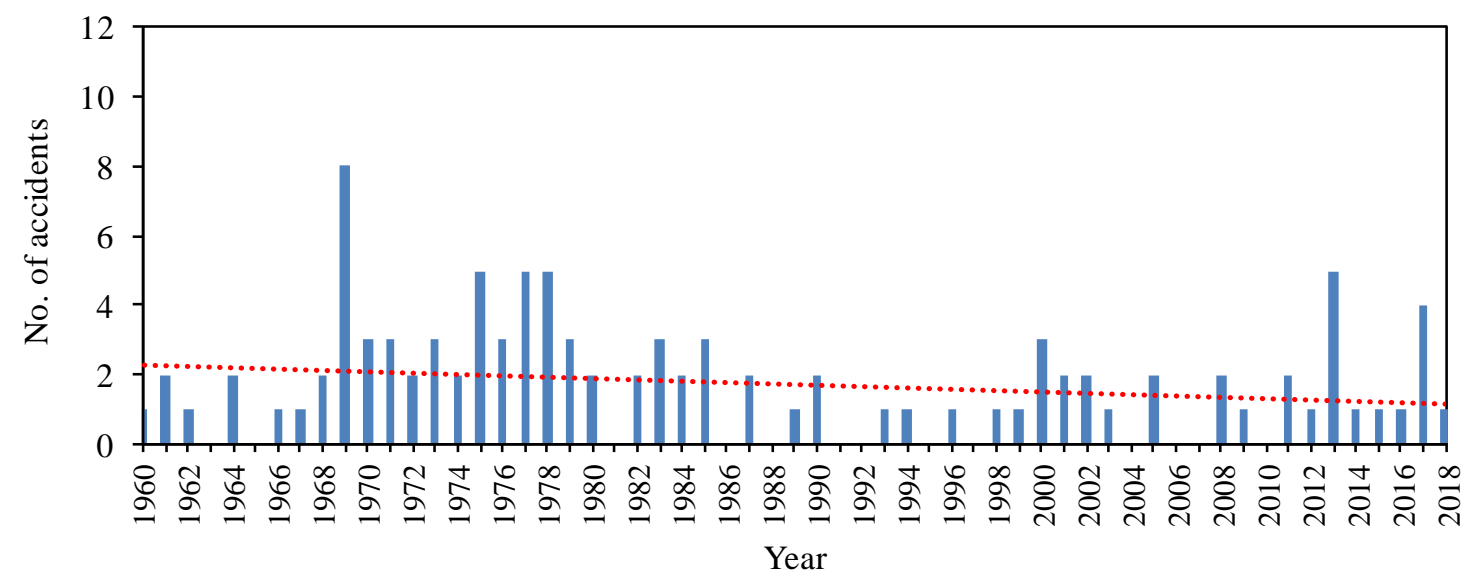

BLEVEs in rest of the world

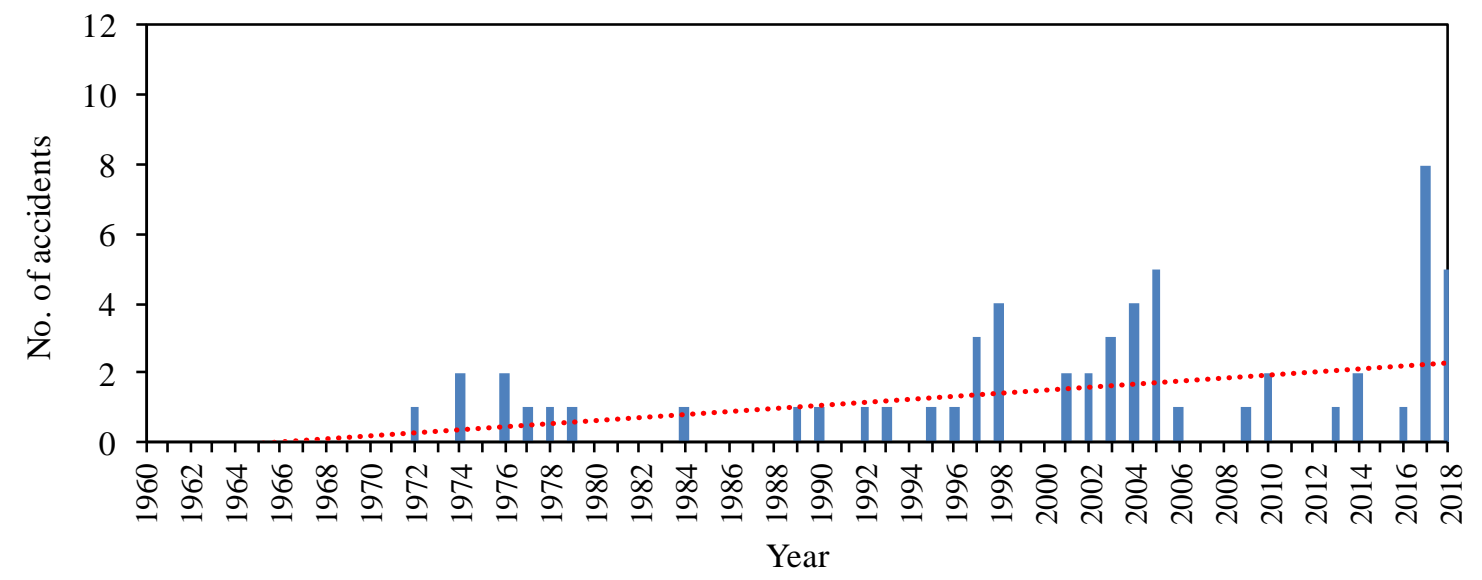

Fig. 3. Trend of BLEVEs occurrence in different parts of the world. 


\subsection{Substances involved}

According to the previous definition (Section 2), it can be expected that substances with boiling temperature lower than ambient temperature -such as light hydrocarbons- are prone to BLEVE. Table 1 shows the substances involved in the 202 BLEVE accidents here analyzed. 282 substances have been identified, as in some of the accidents more than one substance were simultaneously involved (this is why percentages add up to more than 100). As it can be seen in this table, LPG was by large the most frequent material, being found in 59\% of BLEVEs, followed by water (11\%); LNG took part in $4 \%$ of the BLEVE accidents. The high number of accidents involving LPG is due to the (relative) frequency with which road and rail tankers transporting this material have accidents (derailment, collision) that lead to a BLEVE-fireball. As for the $30 \%$ of the category "other chemical substances", it includes but is not limited to: naphtha, isopropyl alcohol, methanol, and ethyl alcohol.

Table 1. Substances involved in BLEVEs

\begin{tabular}{lcc}
\hline Substance & Number of accidents & Percentage \\
\hline LPG & 120 & 59 \\
Water & 22 & 11 \\
Oil & 12 & 6 \\
Vinyl chloride & 11 & 5 \\
Gasoline/Petrol/Diesel/Kerosene & 9 & 5 \\
LNG & 8 & 4 \\
Ethylene oxide & 7 & 4 \\
Carbon dioxide & 6 & 3 \\
Propylene & 5 & 3 \\
Ethylene & 4 & 2 \\
Ammonia & 3 & 2 \\
Chlorine & 3 & 2 \\
Butadiene & 3 & 2 \\
Toluene diisocyanate & 3 & 2 \\
Sodium hydroxide & 3 & 2 \\
Sulfuric acid & 3 & 2 \\
Other chemical substances & 60 & 30 \\
\hline Total & 282 & 2 \\
\hline
\end{tabular}

Concerning water, the following consideration must be done: probably the number of BLEVEs involving it has been much larger than those registered in databases, as the number of steam boilers and hot water tanks is very high in most countries; however, as water is not flammable and therefore it does not originate any subsequent fireball, probably many of such cases had 
not been registered as BLEVEs. Nevertheless, not all steam boiler explosions could be systematically included in the survey, as probably some of them were not a BLEVE; therefore, only those cases registered as such have been included in this survey.

\subsection{General/specific causes}

Understanding the main causes of accidents can be a good mean to prevent further similar accidents. In Table 2, MHIDAS database categories for generic causes were used to identify the causes of BLEVE accidents. The total number of causes were larger than the number of BLEVE accidents because in some accidents there were more than one cause. General causes of accidents were not specified in $37(18.3 \%)$ out of 202 cases; the results in Table 2 correspond thus to 165 accidents. Impact failure $(44.8 \%)$ followed by human factor $(30.3 \%)$ and mechanical failure $(29.1 \%)$ were the main causes.

Table 2. General causes of BLEVEs

\begin{tabular}{|c|c|c|c|c|c|}
\hline General cause & $\begin{array}{c}\text { Number of } \\
\text { accidents }\end{array}$ & $\begin{array}{c}\text { Overall } \\
\text { percentage }\end{array}$ & EU\% & $\begin{array}{c}\text { Other } \\
\text { developed } \\
\text { countries \% }\end{array}$ & $\begin{array}{c}\text { Rest of } \\
\text { the } \\
\text { world \% }\end{array}$ \\
\hline Impact failure & 74 & 44.8 & 17.6 & 67.4 & 19 \\
\hline Human factor & 50 & 30.3 & 41.2 & 19.1 & 42.9 \\
\hline Mechanical failure & 48 & 29.1 & 41.2 & 24.7 & 26.2 \\
\hline External events & 42 & 25.5 & 17.6 & 30.3 & 21.4 \\
\hline Instrument failure & 8 & 4.8 & 8.8 & 4.5 & 2.4 \\
\hline $\begin{array}{l}\text { Violent (runaway) } \\
\text { reaction }\end{array}$ & 5 & 3 & - & 4.5 & 2.4 \\
\hline Service failure & 2 & 1.2 & - & 1.1 & 2.4 \\
\hline $\begin{array}{l}\text { Upset process } \\
\text { conditions }\end{array}$ & 1 & 0.6 & 2.9 & - & - \\
\hline Total & 230 & 139.3 & 129.3 & 151.6 & 116.7 \\
\hline
\end{tabular}

A detailed analysis was also performed by referring to each region. In European countries, mechanical failure $(41.2 \%)$ and human factor $(41.2 \%)$ were the most probable causes of BLEVEs, while in other developed countries it was impact failure (67.4\%). However, human factor $(42.9 \%)$ and mechanical failure $(26.2 \%)$ were the main causes of the accidents in the rest of the world. The high incidence of human factor (30.3\% of all accidents) would indicate the convenience of a higher effort in training operators and improving the safety culture.

Each general cause was subdivided into specific causes in Table 3. Rail accidents (53\%) and road accidents $(26 \%)$ were the most frequent specific ones in impact failure. Regarding human factor, bad maintenance $(33 \%)$ followed by general operation $(14 \%)$ were the main frequent ones. Finally, overheating (33\%) and overpressure (20\%) were was the main specific cause in mechanical failure category. 
Table 3. Specific causes of BLEVEs

\begin{tabular}{|c|c|c|c|}
\hline General cause & Specific cause & $\begin{array}{c}\text { No. of } \\
\text { accidents }\end{array}$ & $\%$ \\
\hline \multirow[t]{6}{*}{ Impact failure $(44.8 \%)$} & Rail accident & 43 & 53 \\
\hline & Road accident & 21 & 26 \\
\hline & Other vehicle & 11 & 14 \\
\hline & Heavy object & 4 & 5 \\
\hline & Excavating equipment & 1 & 1 \\
\hline & Ship to ship collision also barges & 1 & 1 \\
\hline \multirow[t]{9}{*}{ Human factor $(30.3 \%)$} & Bad maintenance & 12 & 33 \\
\hline & General operation & 5 & 14 \\
\hline & Overfilling & 4 & 11 \\
\hline & Management & 4 & 11 \\
\hline & Procedures & 4 & 11 \\
\hline & Failure to connect or disconnect & 2 & 6 \\
\hline & Design error & 2 & 6 \\
\hline & Draining accident & 2 & 6 \\
\hline & $\begin{array}{l}\text { Failure to isolate or drain before } \\
\text { uncoupling }\end{array}$ & 1 & 2 \\
\hline \multirow[t]{11}{*}{ Mechanical failure (29.1\%) } & Overheating & 21 & 33 \\
\hline & Overpressure & 13 & 20 \\
\hline & Corrosion & 5 & 8 \\
\hline & Brittle failure & 4 & 6 \\
\hline & Leaking coupling or flange & 4 & 6 \\
\hline & Hose & 4 & 6 \\
\hline & Relief valve failure & 3 & 5 \\
\hline & Weld failure & 3 & 5 \\
\hline & Leaking or passing valve & 3 & 5 \\
\hline & Metallurgical failure & 2 & 3 \\
\hline & Fatigue & 2 & 3 \\
\hline \multirow[t]{4}{*}{ External events $(25.5 \%)$} & Fire & 33 & 70 \\
\hline & Explosion & 8 & 17 \\
\hline & Temperature extremes & 4 & 9 \\
\hline & Earthquake & 2 & 4 \\
\hline \multirow[t]{2}{*}{ Instrument failure $(4.8 \%)$} & Indicator & 2 & 33 \\
\hline & Trip & 2 & 33 \\
\hline
\end{tabular}


Violent reaction $(3 \%)$

Runaway reaction

Service failure (1.2\%)

Upset process conditions $(0.6 \%)^{1}$

${ }^{1}$ For this case MHIDAS does not have any categories

\subsection{General/specific origin}

The general origin of accidents (Table 4) gives interesting information concerning the activities in which the probability of such accidents is higher; the total percentages of accidents are higher than 100 again, because some accidents had different origins. Overall, transport (43.1\%) and storage area $(20.8 \%)$ obviously had dominant percentages than the other groups. Process plants have a significant contribution as well. The contribution of transport, quite high, is essentially similar to the one already found in a previous survey, 39\% (Abbasi and Abbasi, 2007), and in the analysis of all major accidents (39.1\%, Vílchez et al., 1995). Transfer, essentially loading/unloading operations, was involved in $12.4 \%$ of cases, in most of them through domino effect (see, for example, Demichela et al., 2004).

Table 4. General origin of BLEVEs

\begin{tabular}{lccccc}
\hline General origin & $\begin{array}{c}\text { No. of } \\
\text { accidents }\end{array}$ & $\begin{array}{c}\text { Overall } \\
\text { percentage }\end{array}$ & EU\% & $\begin{array}{c}\text { Other } \\
\text { developed } \\
\text { countries\% }\end{array}$ & $\begin{array}{c}\text { Rest of } \\
\text { the } \\
\text { world\% }\end{array}$ \\
\hline Transport & 87 & 43.1 & 30 & 54.4 & 32.2 \\
Storage area & 42 & 20.8 & 15 & 23.3 & 20.3 \\
Process plant & 33 & 16.3 & 20 & 8.7 & 27.1 \\
Transfer & 25 & 12.4 & 20 & 9.7 & 11.9 \\
Domestic/commercial & 16 & 7.9 & 12.5 & 3.9 & 11.9 \\
premises & 3 & 1.5 & 2.5 & 1 & 1.7 \\
Warehouse & 2 & 1 & 2.5 & 1 & - \\
Disposal area & 208 & 103 & 102.5 & 102 & 105.1 \\
\hline Total & & & & &
\end{tabular}

The general origin of accidents was also investigated for the different parts of the world; transport was the main origin: EU (30\%), other developed countries (54.4\%), and rest of the world $(32.2 \%)$. It was followed by process plants.

The specific origin of the accidents was also studied. According to the data gathered in Table 5, rail tanker $(26.2 \%)$, road tanker $(19.3 \%)$ and pressurized storage vessel $(17.3 \%)$ had the highest percentages. 
Table 5. Specific origin of BLEVEs

\begin{tabular}{lcc}
\hline Specific origin & No. of accidents & Percentage \\
\hline Rail tanker & 53 & 26.2 \\
Road tanker & 39 & 19.3 \\
Pressurized storage vessel & 35 & 17.3 \\
Portable transport container & 18 & 8.9 \\
Steam boiler & 16 & 7.9 \\
Fired process equipment & 8 & 4 \\
On-plant pipes and associated & 6 & 3 \\
valves & & \\
Atmospheric pressure storage & 6 & 3 \\
tank & 5 & 2.5 \\
Heat exchanger & 5 & 2.5 \\
Ship & 4 & 2 \\
Tank container & 4 & 2 \\
Pipeline & 3 & 1.5 \\
Process vessels & 3 & 1.5 \\
Reactor & 5 & 2.5 \\
Other & 210 & 104.1 \\
\hline Total & & \\
\hline
\end{tabular}

\subsection{Affected population}

The affected population is one of the important aspects in safety and risk analysis, and reducing the number of people affected by the BLEVE consequences is the aim of many scientific studies in the field of safety and loss prevention. The affected population can be classified in three groups: fatalities, injuries, and evacuees. The results presented here are just for those cases where information was available (in $76 \%$ of cases for fatalities, for injuries in $78 \%$ and for evacuees in $40.1 \%$ ).

In 154 BLEVEs occurred since 1960, about 1568 people were killed; a detailed study was performed on them. The $p-N$ curve is usually used to represent the lethality of accidents (Fig. 4). In this plot, the number of fatalities $(N)$ is shown on the abscissae and the probability of a BLEVE accident with fatalities equal or greater than $N$ (for $N=1, p=1$ ) is illustrated on its ordinate axis. In fact, the accumulated probability of BLEVE accidents can be represented by this illustrative curve as a function of its severity. The accumulated probability was calculated by the least square method. The resulting function was $p=N^{b}$, with the $b$ value equal to -0.74 . This means that the accumulated probability of BLEVE accidents that causes 10 or more deaths 
is 5.5 times greater than the accumulated probability of BLEVE accidents with 100 or more fatalities.

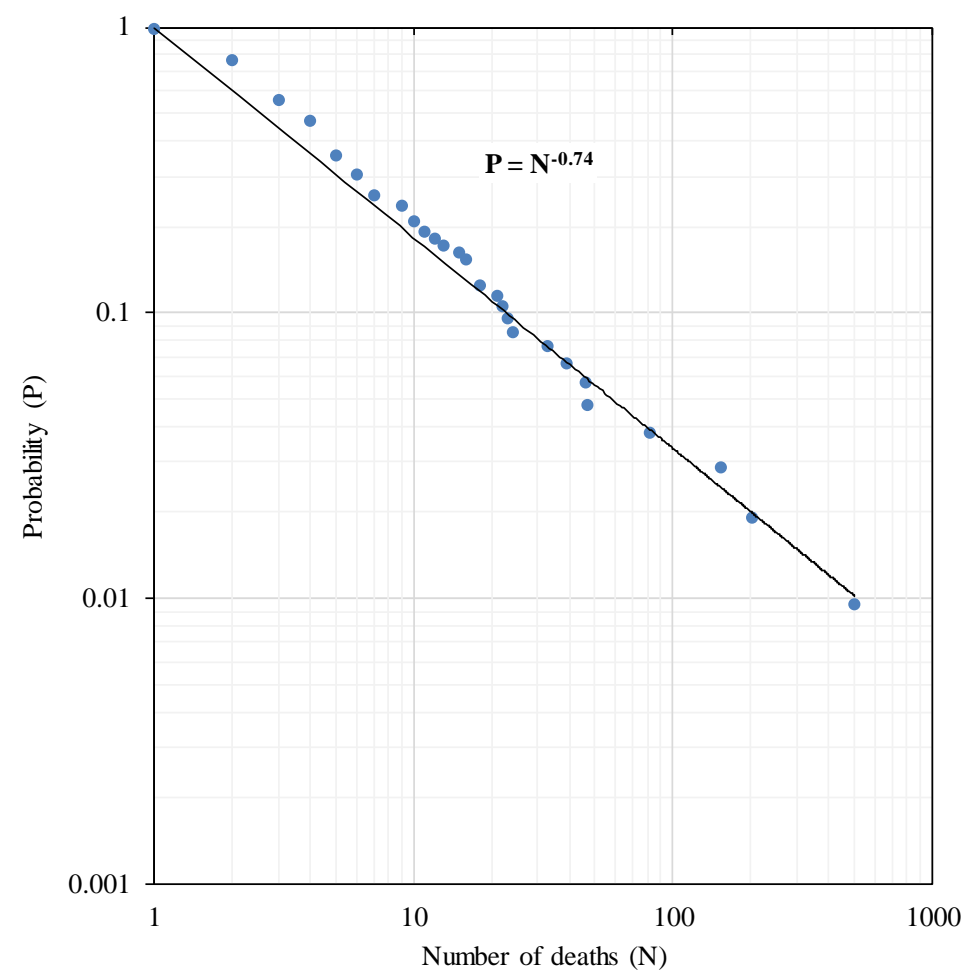

Fig. 4. Accumulated probability as a function of number of deaths for the 104 BLEVEs involving fatalities.

The accumulated probability of fatalities versus the number of deaths was also calculated for different parts of the world (Fig. 5). The accumulated probability of number of deaths is clearly higher for the "rest of the world" (in which case there is a light deviation from the general rule, as often happens, at P values near 1) as compared to that of the EU and the developed countries. It is clear from this plot that the consequences of a severe accident, in terms of lethality, are more important in the developing countries; for example, the probability of having an accident with at least 15 fatalities in a developing country $\left(P_{R}\right)$ is 2.1 times larger than in the developed ones $\left(\mathrm{P}_{\mathrm{D}}\right)$. 


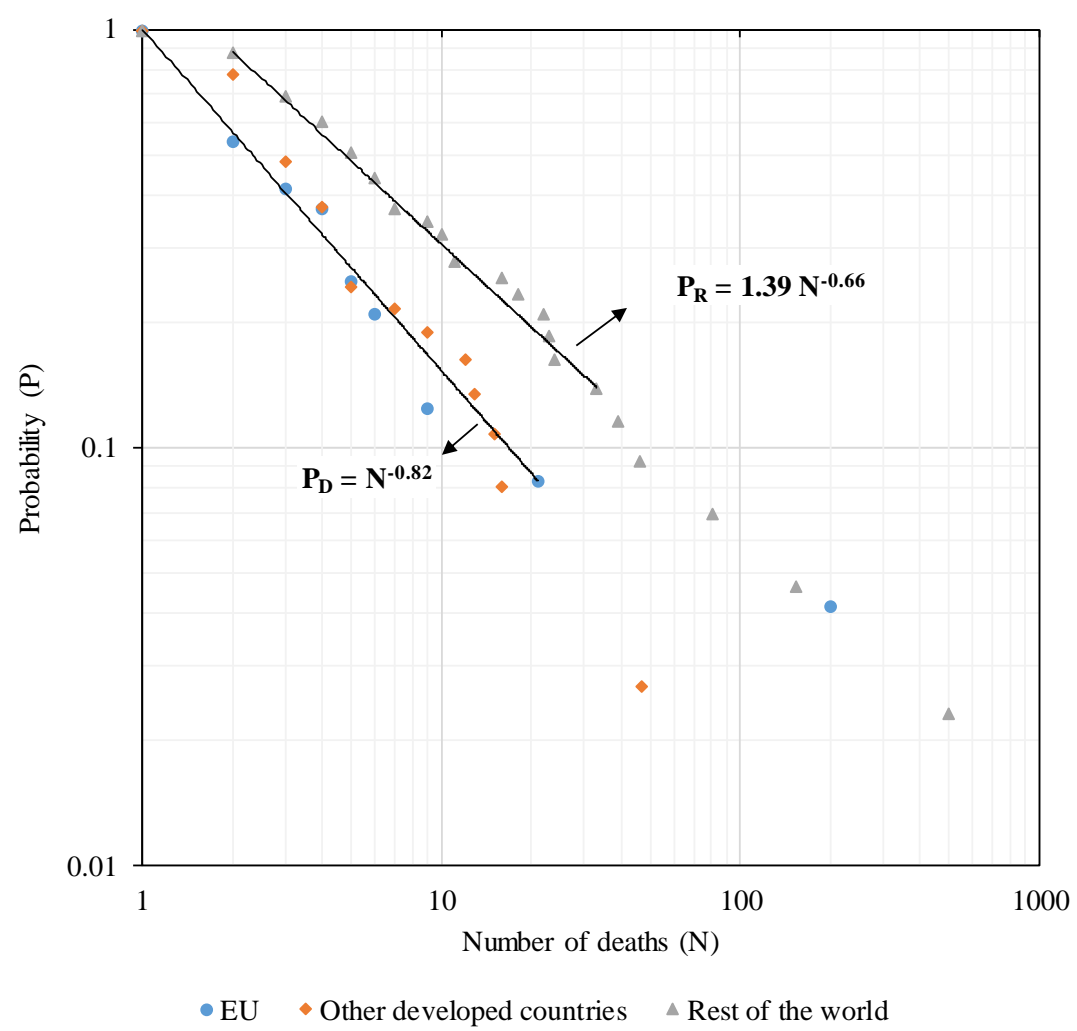

Fig. 5. Accumulated probability as a function of number of deaths according to the development degree of the countries.

The analysis of the number of injuries in the accidents (Table 6) showed that only $24.2 \%$ of accidents had no injured and $40.8 \%$ of accidents had between 1 and 10 injured; in $29.9 \%$ of cases there were between 11 and 100 injured; and only 5.1\% had more than 100 injured people.

Table 6. BLEVEs injured

\begin{tabular}{lcc}
\hline Injured & No. of accidents & Percentage \\
\hline No injuries & 38 & 24.2 \\
$1-10$ & 64 & 40.8 \\
$11-100$ & 47 & 29.9 \\
$101-1000$ & 7 & 4.5 \\
$>1000$ & 1 & 0.6 \\
\hline Total & 157 & 100 \\
\hline
\end{tabular}

Further analysis (Table 7) showed that in $48.1 \%$ of BLEVE accidents there were no evacuees, in $18.5 \%$ there were between $1-100$, in $13.6 \%$ there were between $101-1000$, in $13.6 \%$ there were between $1001-10,000$, and in only $6.2 \%$ of accidents there were more than 10,000 people evacuated. 
Table 7. BLEVEs evacuees

\begin{tabular}{lcc}
\hline Evacuees & No. of accidents & Percentage \\
\hline No evacuees & 39 & 48.1 \\
$1-10$ & 11 & 13.6 \\
$11-100$ & 4 & 4.9 \\
$101-1000$ & 11 & 13.6 \\
$1001-10,000$ & 11 & 13.6 \\
$>10,000$ & 5 & 6.2 \\
\hline Total & 74 & 100 \\
\hline
\end{tabular}

As a final comment to the consequences on people, the following should be taken into account: in the event of a BLEVE followed -as often happens- by a fireball, most of the consequences -fatalities, injured people- are associated to the thermal radiation from the fireball. As an example, the following case can be mentioned (Birk et al., 2013): the explosion-fireball of a spherical tank with a volume of $2000 \mathrm{~m} 3$ containing propane, at different filling degrees. These authors calculated the distance at which a peak overpressure of 0.3 bar (often accepted in quantitative risk analysis as the overpressure implying a 100\% lethality for both direct and indirect effects) would be reached, as well as the corresponding fireball diameter and duration; the values for two filling degrees can be seen in Table 8 .

Table $8.100 \%$ lethality distances

\begin{tabular}{ccccc}
\hline Filling degree & $\begin{array}{c}\text { Distance to 0.3 } \\
\text { bar* }(\mathbf{m})\end{array}$ & $\begin{array}{c}\text { Fireball } \\
\text { diameter* } \\
(\mathbf{m})\end{array}$ & Time* $(\mathbf{s})$ & $\begin{array}{c}\text { Distance }-\mathbf{1 0 0 \%} \\
\text { lethality**(m) }\end{array}$ \\
\hline 0.2 & 82 & 377 & 28 & 360 \\
0.8 & 107 & 531 & 40 & 650 \\
\hline
\end{tabular}

*Birk et al., $2013 * *$ This work

For a filling degree of $20 \%$ the distance at which $\Delta \mathrm{P}=0.3$ bar was $82 \mathrm{~m}$ and the fireball diameter was $377 \mathrm{~m}$; and for a filling degree of $80 \%$, the distance was $107 \mathrm{~m}$ and the diameter $531 \mathrm{~m}$. If, for these two fireballs we calculate the distance at which the lethality due to the thermal radiation would be $100 \%$ we obtain $360 \mathrm{~m}$ and $650 \mathrm{~m}$, respectively. It is clear, therefore, that in most cases (except for the linear ejection of fragments) the consequences on people due to the fireball will be much more severe than those due to overpressure wave.

\section{Conclusions}

Two aspects concerning BLEVEs have been analyzed: first, the main features of those explosions involving water -which have received relatively low attention in the literature- and, secondly, the main features of the BLEVE occurrence as a function of the materials involved, causes, origin and consequences on people.

The case of water is especially interesting: although many steam boiler explosions are probably BLEVEs (but not all: some of them are associated to combustion chamber explosions), they 
are not registered as such due to the fact that they are not followed by a fireball; this is why they are underrepresented in this type of surveys. Nevertheless, the energy released from a water BLEVE will be significantly stronger than that originated by the same amount of other substances such as, for example, LPG; and, therefore, the corresponding overpressure wave and the peak overpressure will also be higher. This is essentially due to the higher volume change associated both to the vapor expansion and to the liquid vaporization for the case of water; a comparison with propane values clearly demonstrates this.

The historical analysis of 202 cases has shown that the most common substance associated with BLEVE is LPG. As for the general origin of these events, transport is the most common activity, followed by storage and process plants; transfer (loading/unloading) keeps having an overall value of approximately $12 \%$, as already found in other surveys on major accidents.

According to this information, a further effort should be made to reduce the risk in the transportation of LPG and LNG by road and rail; in this regard, the increasing use in certain countries of double wall tanks would be quite positive. The prediction of the BLEVE frequency (necessary for a quantitative risk analysis) could probably be estimated for both road and rail transport by performing an accurate analysis of all accidents occurred in these transportation modes in diverse countries (traffic accident and derailment frequency, frequency of BLEVE in the event of such accidents). This could be studied in future research, as well as its relationship with the existing regulations and procedures and their possible improvement.

Some attention should also be devoted to loading/unloading operations: even if it is well known that they are dangerous and the responsible of approximately $10 \%$ of all major accidents, BLEVEs keep occurring during them. So, an effort should be applied to analyze and improve the procedures and safeguards in these operations.

Finally, the analysis of the frequency of BLEVEs in the different world regions could be associated with the positive influence of the regulations existing in the developed countries. Concerning the developing ones, besides a possible improvement of these regulations in certain cases, the influence of the increase in their population and of the "Industrialization Intensity Index" have probably an important influence on the higher incidence of the accidents.

\section{Acknowledgments}

This research was partially funded by the Spanish Ministry of Economy and Competitiveness (projects CTM2014-57448-R and CTQ2017-85990-R, co-financed with FEDER funds), by the Institut d'Estudis Catalans (Project PRO2018-S03) and by National Elites Foundation (Iran).

\section{References}

Abbasi, T., Abbasi, S. A., 2007. The boiling liquid expanding vapour explosion (BLEVE): Mechanism, consequence assessment, management. J. Hazard. Mater., 141(3), 489519. https://doi.org/10.1016/j.jhazmat.2006.09.056

Abdolhamidzadeh, B., Abbasi, T., Rashtchian, D., Abbasi, S. A., 2011. Domino effect in process-industry accidents. An inventory of past events and identification of some patterns. J. Loss Prev. Process Ind., 24 (5) 575-593.

ARIA., 2012. Analysis, Research and Information on Accidents, Retrieved 10/04/2013, from www.aria.developpement-durable.gouv.fr. 
Bernatík, A., Senovsky, P., Pitt, M., 2011. LNG as a potential alternative fuel-safety and security of storage facilities. J. Loss Prev. Process Ind., 24(1), 19-24. https://doi.org/10.1016/i.jp.2010.08.003

Birk, A. M., Poirier, D., Davison, C., 2006. On the response of 500 gal propane tanks to a $25 \%$ engulfing fire. J. Loss Prev. Process Ind., 19, 527-541.

Birk, A. M., Ye, Z., Maillette, J., Cunningham, M., 1993. Hot and cold BLEVEs: observation and discussion of two different kinds of BLEVEs. In AIChE Symposium Series (pp. 119-119). AMERICAN INSTITUTE OF CHEMICAL ENGINEERS.

Birk, A. M., Davison, C., Cunningham, M., 2007. Blast overpressures from medium scale BLEVE tests. J. Loss Prev. Process Ind., 20(3), 194-206. https://doi.org/10.1016/j.jlp.2007.03.001

Birk, A. M., Dusserre, G., Heymes, F., 2013. Analysis of a propane sphere BLEVE. Chem. Eng. Trans., 31, 481-486. https://doi.org/10.3303/CET1331081

Birk, A. M., Heymes, F., Eyssette, R., Lauret, P., Aprin, L., Slangen, P., 2018. Near-field BLEVE overpressure effects: The shock start model. Process Saf. Environ. Prot., 116, 727-736. https://doi.org/10.1016/i.psep.2018.04.003

Bubbico, R., Marchini, M., 2008. Assessment of an explosive LPG release accident: a case study. J. Hazard. Mater., 155(3), 558-565. https://doi.org/10.1016/j.jhazmat.2007.11.097

Casal, J., Salla, J. M., 2006. Using liquid superheating energy for a quick estimation of overpressure in BLEVEs and similar explosions. J. Hazard. Mater., 137 (3) 1321-1327. https://doi.org/10.1016/i.jhazmat.2006.05.001

CCPS, Center for Chemical Process Safety, ed., 1994. Guidelines for evaluating the characteristics of vapor cloud explosions, flash fires and BLEVEs. AIChE

CSB. U.S. Chemical Safety Board, 2012. Retrieved 10/04/2013, from www.csb.gov.

Darbra, R. M., Palacios, A., Casal, J., 2010. Domino effect in chemical accidents: main features and accident sequences. . J. Hazard. Mater., 183 (1-3) 565-573.

Demichela, M., Piccinini, N., Ooggio, A., 2004. Analysis of an LPG accidental release. Process saf. Environ. Prot., 82 (B2), 128-131.

FACTS. Failure and ACidents Technical information System (FACTS), 2010. Retrieved 10/04/2013, from www.factsonline.nl.

Hemmatian, B., Casal, J., Planas, E., 2017. A new procedure to estimate BLEVE overpressure. Process Saf. Environ. Prot., 111, 320-325. https://doi.org/10.1016/i.psep.2017.07.016

Hemmatian, B., Planas, E., Casal, J., 2015. Fire as a primary event of accident domino sequences: the case of BLEVE. RELIAB. ENG. SYST. SAFE., 139, 141-148. https://doi.org/10.1016/j.ress.2015.03.021

Hemmatian, B., Abdolhamidzadeh, B., Darbra, R. M., Casal, J., 2014. The significance of domino effect in chemical accidents. J. Loss Prev. Process Ind., 29, 30-38. https://doi.org/10.1016/i.jp.2014.01.003

Johnson, D. M., Pritchard, M. J., Wickens, M. J., 1990. Large scale catastrophic releases of flammable liquids. Brish Gas Report to the CEC, Contract EV4T, 14. 
Laboureur, D., Birk, A. M., Buchlin, J. M., Rambaud, P., Aprin, L., Heymes, F., Osmont, A. , 2015. A closer look at BLEVE overpressure. Process Saf. Environ. Prot., 95, 159-171. https://doi.org/10.1016/j.psep.2015.03.004.

MARS. Accident Reporting System (MARS), 2012. Retrieved 10/04/2013, from emars.jrc.ec.europa.eu.

MHIDAS. Major Hazardous Incident Data Service, 2007. In AEA techhnology. London. HSEHealth and Safety Executive, UK.

Napier, D. H., Roopchand, D. R., 1986. An approach to hazard analysis of LNG spills. $J$. Occup. Accid., 7(4), 251-272. https://doi.org/10.1016/0376-6349(86)90017-9

NFPA. National Fire Protection Association (NFPA), 2012. Retrieved 10/04/2013, from www.nfpa.org.

NTSB. U. S. National Transport Safety Board, 2013. Retrieved 10/04/2013, from www.ntsb.gov.

Pitblado, R. M., Woodward, J. L., 2011. Highlights of LNG risk technology. J. Loss Prev. Process Ind., 24(6), 827-836. https://doi.org/10.1016/i.jp.2011.06.009

Planas-Cuchi, E., Salla, J. M., Casal, J., 2004. Calculating overpressure from BLEVE explosions. J. Loss Prev. Process Ind., 17(6), 431-436. https://doi.org/10.1016/i.jp.2004.08.002

Prugh, R. W., 1991. Quantitative Evaluation of" Bleve" Hazards. J. Fire Prot. Eng., 3(1), 924. https://doi.org/10.1177/104239159100300102

Reid, R. C., 1979. Possible mechanism for pressurized-liquid tank explosions or BLEVE's. Science, 203(4386), 1263-1265. https://doi.org/10.1126/science.203.4386.1263

Salla, J. M., Demichela, M., Casal, J., 2006. BLEVE: a new approach to the superheat limit temperature. J. Loss Prev. Process Ind., 19(6), 690-700. https://doi.org/10.1016/i.jp.2006.04.004

Scarponi, G. E., Landucci, G., Birk, A. M., Cozzani, M., 2018. LPG vessels exposed to fire: scale effects on pressure build-up. J. Loss Prev. Process Ind., 56, 342-358.

https://doi.org/10.1016/j.jlp.2018.09.0015

Vílchez, J. A., Sevilla, S., Montiel, H., Casal, J., 1995. Historical analysis of accidents in chemical plants and in the transportation of hazardous materials. J. Loss Prev. Process Ind., 8(2), 8796. 